\title{
Administração pública sob a ótica dos estudos críticos: reflexões, interlocuções e tendências
}

\section{Public administration from the perspective of critical studies: reflections, dialogues and trends}

Josiel Lopes Valadares

Doutorado em Administração pela Universidade Federal de Lavras (UFLA). Prof. Adjunto. Departamento de Administração e Contabilidade. Universidade Federal de Viçosa, Brasil,

adm_josiel@yahoo.com.br,

http://llattes.cnpq.br/4460783445382011

\section{Lauisa Barbosa Pinto}

Doutoranda em Administração pela Universidade Federal de Lavras (UFLA). Professora no Instituto Federal de Educação, Ciência e Tecnologia do Sul de Minas Gerais - Campus Pouso Alegre

Brasil,

lauisa-adm@hotmail.com,

http://lattes.cnpq.br/0579675835197932

Ana Alice Vilas Boas

Pós-Doutorado pela École des Hautes Études Commerciales HEC-Canada. Professora Associada, Departamento de Administração e Economia Universidade Federal de Lavras, Brasil,

ana.alice@dae.ufla.br,

http://llattes.cnpq.br/5461876529687716

Mozar José Brito

Doutorado em Administração pela Universidade de São Paulo. Prof. Titular, Departamento de Administração e Economia da Universidade Federal de Lavras, Brasil,

mozarjdb@dae.ufla.br

http://lattes.cnpq.br/1942580852256588

RESUMO: Neste artigo propõe-se investigar o emprego de abordagens críticas por pesquisadores da área de administração pública no Brasil. Para tanto, foi realizada uma pesquisa bibliográfica em três bases de dados (Web of Science, Scopus e Scielo) de reconhecida reputação acadêmica. A análise textual evidenciou que os pesquisadores da referida área de conhecimento têm apropriado de abordagens críticas, apontando possibilidades e tendências de aplicação de categorias conceituais oriundas de diferentes abordagens. Entre elas destacam-se a noção de razão crítica, emancipação e práxis, relações de poder e dominação, dentre outros. Em termos metodológicos os pesquisadores têm procurado: valorizar as experiências locais; promover a interlocução entre teoria e prática; e, construir novas possibilidades de aproximação e integração entre pesquisadores e sujeitos coletivos.

Palavras-Chave: Estudos Críticos; Avaliação Sistemática; Administração Pública.

ABSTRACT: This article has the purpose of investigating the use of critical approaches by researchers of the public administration in Brazil. In order to achieve this, a literature review was carried out in three databases of outstanding academic reputation (web of Science, Scopus and Scielo). The literature analysis showed that the researchers from that specific area of knowledge have adopted critical approaches, pointing out possibilities and trends in the application of conceptual categories from different perspectives. Among them, we could notice the presence of various concepts, such as critical thinking, emancipation, praxis, powe relations and domination relations. In terms of methodology, the researchers aspire to value local experience, to promote a dialogue between theory and practice and to build new possibilities of approximation and integration between researchers and collective actors.

Keywords: Critical Studies; Systematic review; Public Administration.

Texto completo em português: http://www.apgs.ufv.br Full text in Portuguese: http://www.apgs.ufv.br

\section{Introdução}

No contexto da administração pública no Brasil, a discussão de matrizes ontológicas e epistemológicas, tem sido levantada nos últimos anos por um grupo de pesquisadores como Keinert (1994), Fadul, Silva, e Silva (2012) e Andion (2012), que relatam a importância de compreensão do campo por um olhar multifacetado, para que tenhamos uma distribuição mais equitativa dos recursos disponíveis frente às demandas e interlocuções entre Estado, Mercado e Sociedade. Especificamente, esses pesquisadores apontam um predomínio "do paradigma funcionalista no campo da administração pública brasileira", e que existe "a necessidade de se pensar novos caminhos metateóricos pouco explorados [...] tendo como inspiração referenciais críticos e interpretativos" (Andion, 2012, p. 1). Além disso, Box (2005) enuncia que na área de administração pública existe uma escassez de trabalhos que utilizam abordagens críticas - aqui especificamente a teoria crítica como norteadora dos estudos na administração pública.

De maneira específica, a teoria crítica na administração é relacionada aos estudos realizados pela Escola de Frankfurt (Nobre, 2011). No entanto, para Domingues (2011, p. 83) a teoria crítica "pode e deve se renovar, a fim de lidar com as grandezas e misérias da modernidade contemporânea, contribuindo para que reencontre as avenidas da mudança social progressista" (Domingues, 2011, p.83). Portanto, na perspectiva de Alcadipani e

Correspondência/Correspondence: Josiel Lopes Valadares, Rua da Mantiqueira, 95, apt 601, Bairro João Braz. CEP: $36570-000$ - Viçosa - MG. adm_josiel@yahoo.com.br, 
Tureta (2009) é possível ver, na administração, uma abordagem crítica que congrega as contribuições de autores como Antônio Gramsci, Karl Marx, Paulo Freire, Jürgen Habermas, Bruno Latour, Guerreiro Ramos, bem como os termos marxismo, pósestruturalismo, teoria crítica, pluralismo, reflexividade, emancipação e práxis libertadora. Domingues (2011) corrobora com essa visão não restringindo a teoria crítica a esta tradição e à delimitação de 'marxismo ocidental'. Para o autor a teoria crítica pode ser vista de forma mais ecumênica.

Nesta composição, a teoria crítica, passa a ser conceituada como "uma vertente de questionamento da modernidade que sustenta não apenas seus valores contra as instituições do tempo presente, mas também que busca localizar nele, bem como nos agentes sociais que dentro dele se movem, os potenciais e possíveis sujeitos da emancipação prometida anteriormente pela modernidade" (Domingues, 2011, p.72). Vista nesta perspectiva ampla, é possível também observar nas abordagens críticas as influências da teoria da complexidade com Edgar Morin (Francelin, 2005; Serva, Dias e Alperstedt, 2010), as influências de HansGeorg Gadamer e Paul Ricoeur, com a hermenêutica crítica (Prasad, 2002; Mcclaren \& Mills, 2010) e com Edmund Husserl e Martin Heidegger com a fenomenologia (Boava \& Macedo, 2011). Para Alcadipani e Tureta (2009) essa diversidade de ontologias e epistemologias presentes na abordagem crítica faz da mesma uma corrente que consegue analisar de forma mais rica e complexa as problemáticas inseridas tanto na sociedade quanto nas organizações.

Apesar de este artigo partir do pressuposto de uma teoria crítica mais ampla e não querer restringir a teoria crítica à tradição da Escola de Frankfurt, para Paes de Paula (2013) aquela tem um papel importante para a abordagem crítica, pois, através de suas três gerações ela apresenta obras que se tornam fundamentais para a compreensão das mazelas da sociedade e das organizações contemporâneas. O texto seminal desta teoria foi 'Teoria Crítica e Teoria Tradicional' de Horkheimer publicado em 1937. $\mathrm{Na}$ concepção de Horkheimer (1975), a teoria tradicional propicia a base para a ordem existente impedindo a emancipação.

Neste sentido, "o cientista e sua ciência estão atrelados ao aparelho social, suas realizações constituem o momento de autopreservação e da reprodução contínua do existente" (Horkheimer, 1975, p. 131). A ciência, desta forma, "operaria da mesma maneira que a economia capitalista, naturalizando construções sociais e perpetuando formas de dominação sob a aparência da neutralidade" (Mendonça, 2013, p. 51). Horkheimer afirma, desta maneira, que "a filosofia e a Ciência Crítica deveriam desnaturalizar o mundo para transformá-lo. O papel da Teoria Crítica seria desvelar o modo como a estrutura social coíbe a autonomia dos sujeitos, revelando conceitos chave que fomentem a emancipação humana" (Mendonça, 2013, p. 51). Em outra obra importante - A Dialética do Esclarecimento -, Adorno e Horkheimer (1985) apresentam a ciência, quando aliada à filosofia moderna, como instrumento opressor. A construção moderna da ideologia do pensamento científico, esboçada no pressuposto de neutralidade, estabelece o alcance das classes economicamente dominantes. $\mathrm{Na}$ visão de Mozzato e Grzybovski (2013) a crítica habermasiana vai ao encontro da crítica de Adorno e Horkheimer (1985) ao demonstrar que a racionalidade instrumental passa a ser utilizada em direção contrária à emancipação humana, atendendo aos interesses de elitistas (Habermas, 1987). Dessa forma, a construção moderna da ideologia do pensamento científico esboça um caráter de neutralidade estabelecendo o alcance das classes economicamente dominantes (Faria e Meneghetti, 2010, p. 41).

Dentro do contexto da Escola de Frankfurt para Paes de Paula (2008) o grande norte de sua teoria crítica seria o conceito de emancipação. A luta contra injustiça social torna-se central para a essa teoria, tendo por missão unir teoria e prática através da práxis. Segundo a autora, desta maneira, o objetivo da teoria crítica"[...] é promover a reflexividade e uma nova base para a práxis, que uniria teoria e prática" (Paes de Paula, 2008, p. 2).

$\mathrm{Na}$ visão de Faria (2009, p. 512), a teoria crítica tem como objetivo central:

"esclarecer em que medida as instâncias obscuras (que se operam nos bastidores organizacionais, nas relações subjetivas e no inconsciente individual) e manifestas (especialmente, as referentes ao regramento e às estruturas formais) dão conteúdo às configurações do poder nas organizações do ponto de vista do sujeito coletivo do trabalho". (Faria, 2009, p. 512)

Desse modo, a teoria crítica passa a ter um papel de revelar as formas como as organizações criam "racionalidades (de regras, objetivos, políticas, processos produtivos, planos, estratégias etc.) e [...] (inter) subjetividades (símbolos, ritos, imaginários e mitos), com seus paradoxos e contradições (Faria, 2009, p. 512)".

Segundo Paes de Paula (2013), na administração, tem-se a expectativa de que produza conhecimentos técnicos, podendo utilizá-los na vida cotidiana. No entanto, a crítica interna à teoria crítica tem sido pelo fato da mesma isolar-se do homem da rua, "pois em geral estes trabalhos são tomados como puramente teóricos e afastados da prática, além de realizarem críticas sem apontar saídas" (Paes de Paula, 2013, p. 521). Autores como Marsden e Townley (2001), Misoczky e Amantino-de-Andrade (2005), Paes de Paula, Maranhão e Barros (2009), Alcadipani e Rosa (2010), Bertero et al., (2013), evidenciam que a prática de construção do conhecimento de maneira afastada das vicissitudes cotidianas pode ser caracterizada pela metáfora torre de marfim que é permeada pelos "[...] seus debates assépticos e polidos, [...] que não se contamina com as mazelas do mundo" (Misoczky e Amantino-de-Andrade, 2005, p. 224). Apesar desta conotação, destaca-se neste trabalho o potencial da teoria crítica em descortinar a falsa dicotomia entre teoria e prática existente na Teoria Tradicional, e avançar na direção da práxis como categoria central nos estudos (ou abordagem) críticos, já que articula pensamento e ação, e por consequência, dialética e crítica (Paes de Paula, 2008).

Na perspectiva de Sousa Santos (1999), o problema que mais intriga as ciências sociais é: por que se tornou tão difícil produzir uma teoria crítica? Segundo o autor, apesar de a sociedade em geral estar se modificando num mundo onde há tanto para criticar, 
a crítica torna-se muito difícil. Na perspectiva do autor, a teoria crítica poderia ser entendida como a teoria que não reduz a "realidade" ao que existe.

Especificamente no campo da Administração Pública, a análise empreendida por Box (2005), evidencia que os diálogos com a teoria crítica ainda são incipientes. Apesar das problemáticas presentes na sociedade, e na administração pública atual, não é tão presente os estudos que utilizam da abordagem crítica como pressuposto epistemológico. No entanto, segundo o autor, a teoria crítica tem muito a contribuir para a análise de problemas como pobreza, guerras, violência, destruição do meio ambiente, desigualdades sociais e outras problemáticas encontradas na administração pública. Vê-se nas abordagens críticas, então, a possibilidade da compreensão da administração pública de maneira plural. Deste modo, isto coaduna com as necessidades do campo da administração pública, que embora tem na gestão um fator essencial para sua organização e sobrevivência, vê-se imerso numa situação onde os interesses sociais, políticos e contextuais influencia, sobretudo, na maneira de atuação do agente público.

Diante deste contexto, e pensando no processo de construção, delineamento e desenvolvimento do campo da administração pública em relação às dimensões ontológica, epistemológica e de forma (inter) disciplinar, busca-se, nesta pesquisa, investigar se e como as abordagens críticas vêm sendo utilizada em estudos na área de administração pública no Brasil e no mundo. O intuito é utilizar os artigos selecionados para ampliar o debate sobre as interlocuções entre teoria crítica e administração pública, atentando-se para as possibilidades e tendências de estudos na área.

Para tanto, parte-se do pressuposto que as diferentes epistemologias (hard ou soft) podem se complementar com o conhecimento humano acerca daquilo que se está estudando. Em outros termos, parte-se do pressuposto que seja possível estabelecer um diálogo entre as possibilidades epistemológicas a partir do olhar da integração, e não da dicotomização dos mesmos (Santos, 1999). Busca-se, desta maneira, evidenciar o debate sobre as abordagens críticas e a administração pública, a partir do pressuposto de que as abordagens críticas são amplas e reveladoras. Os estudos críticos (aqui entendido de forma mais ecumênica - conforme Domingues, 2011) se destacam por investigar mais do que as racionalidades instrumentais, que as estratégias, que as instituições, que os comportamentos e que as políticas. O papel dos estudos críticos consiste em desvendar o mundo do poder e as formas de controle econômico, jurídicopolítico, ideológico e psicossocial sobre o processo e a divisão do trabalho, para se sentirem autorizados a compreender as organizações e suas finalidades (Adler, Forbes \& Wilmott, 2007). Neste ínterim é possível observar este tipo de estudo lidando com uma análise contra hegemônica em relação às formas de dominação da sociedade representadas pelo capitalismo, pelo patriarcado, pelo racismo, pelo imperialismo, pelo gerencialismo e pelo produtivismo.
Para atingir este objetivo, este trabalho foi construído em mais três seções além desta introdução. Primeiramente, expõe o percurso metodológico utilizado neste trabalho delimitando as principais estratégias de coleta e análise de dados. Logo após evidenciam-se os principais resultados encontrados a partir da análise de cada um dos trabalhos selecionados, e, por fim, são construídas as considerações e conclusões a partir dos artigos selecionados.

\section{Procedimentos Metodológicos}

Neste artigo empregou-se a revisão sistemática. Este tipo de método tem sido utilizado por várias pesquisas, em diversas áreas, como possibilidade metodológica qualitativa para compreender a construção de determinados campos. Dentre elas, podemos perceber os estudos de Barroso et al., (2003); Berwanger (2007); Lopes e Fracolli (2008); Tummers e Karsten (2011); Lehner e Kaniskas (2012); Zoltowski (2014). A revisão sistemática torna-se uma avaliação rigorosa das pesquisas realizadas dentro de um tema específico (Cook et al., 1997). Em termos conceituais, a revisão bibliográfica sistemática é vista como um instrumento de mapeamento de trabalhos publicados sobre um tema de pesquisa específico, permitindo ao pesquisador elaborar uma síntese do conhecimento existente sobre o assunto e visando a compreensão do "estado da arte" do assunto pesquisado. Conforto et al., (2011, p. 3) definem a revisão bibliográfica sistemática como

"o processo de coletar, conhecer, compreender, analisar, sintetizar e avaliar um conjunto de artigos científicos com o propósito de criar um embasamento teórico-científico (estado da arte) sobre um determinado tópico ou assunto pesquisado". (CONFORTO et al., 2011, p. 3)

No caso desta pesquisa, os procedimentos adotados para sua realização foi o levantamento de artigos que utilizavam a abordagem crítica como estratégia de pesquisa, ou tema principal, em periódicos da área de administração. Escolheu-se as bases Web of Science, Scopus e Scielo como fontes de dados de pesquisa, devido à importância e a representatividade no cenário nacional e internacional em ciências sociais, e especificamente para a administração pública. Além disso, vale ressaltar que, utilizando deste recorte, a pesquisa baseia-se, sobretudo, nos principais periódicos presentes no contexto da administração pública, em nível internacional e nacional. Isto quer dizer que podem existir pesquisas não analisadas e de bom valor, que não foram analisadas neste artigo, dado que não estiveram indexadas nas plataformas utilizadas. Apesar de reconhecer esta limitação, compreende-se que isto não impediu de alcançar o objetivo deste trabalho.

$\mathrm{Na}$ Web of Science buscou-se os artigos presentes nos periódicos relacionados à public administration; na Scopus os artigos escolhidos foram àqueles presentes na categoria social sciences \& humanities e na subcategoria business, management and accounting e; na Scielo a busca se baseou naqueles presentes na categoria 'ciências sociais aplicadas' e posteriormente em 'administração pública'. As palavras utilizadas na busca foram critical e public administration. 
Em termos temporais, investigaram-se as publicações no período de cinco anos (2010 a 2014), em cada base de pesquisa. Na primeira etapa de pesquisa foram encontrados 47 (quarenta e sete) artigos na Web of Science, 45 (quarenta e cinco) na Scopus e 29 (vinte e nove) artigos na Scielo, totalizando 121 (cento e vinte um) artigos. Já na Instituição de Ensino Superior pesquisada tivemos acesso a 25 (vinte e cinco) artigos na Web of Science, 26 (vinte e seis) artigos na Scopus e 25 (vinte e cinco) artigos na Scielo, totalizando 76 (setenta e seis) artigos, que formarão a base de dados para primeira etapa deste trabalho. A pesquisa foi realizada entre os meses de janeiro a março de 2014, sendo realizados 3 (três) pré-testes até chegar a base de dados utilizada.

A segunda etapa consistiu na análise de quais destes artigos enquadravam-se ao escopo de pesquisa, ou seja, quais dos artigos poderiam ser vistos como críticos. Frente a esse filtro, restaram 9 (nove) artigos na Web of Science, 5 (cinco) artigos na Scopus, e 8 (oito) artigos na Scielo. Na próxima seção serão analisados os 22 (vinte e dois) artigos encontrados. O critério de escolha dos artigos que compõem a base para análise foi aqueles que utilizaram a abordagem crítica (em termos amplos) e a administração pública para problematização do artigo.

\section{Estudos Críticos e a Produção do Conhecimento em Administração Pública}

Os artigos selecionados são provenientes de alguns dos mais importantes periódicos da administração pública no mundo, e no Brasil, como: Administration \& Society, Public Administrative Review, Public Administration, The American Review of Public e Revista de Administração Pública. No decorrer desta seção serão analisados, de forma detalhada, os 25 (vinte e cinco) trabalhos selecionados na segunda etapa de pesquisa. A análise dos trabalhos selecionados acontecerá em três blocos. O primeiro será composto pelos artigos relacionados no quadro 1 , provenientes da base Web of Science.

Quadro 1: Artigos selecionados na Web of Science

\begin{tabular}{|c|c|c|}
\hline Periódico & Títulos & Ano \\
\hline \multirow[t]{3}{*}{ Administration \& Society } & $\begin{array}{l}\text { 1. What Are "Great Books" in the Study of Public Administration? Some Polemic } \\
\text { Thoughts About the Surveys of Sherwood and Kasdan }\end{array}$ & 2012 \\
\hline & $\begin{array}{l}\text { 2. Downsides of Social Capital for Women During Disaster Recovery: Toward a } \\
\text { More Critical Approach }\end{array}$ & 2013 \\
\hline & $\begin{array}{l}\text { 3. The Future of Public Administration: Challenges and Opportunities-A Critical } \\
\text { Perspective }\end{array}$ & 2012 \\
\hline $\begin{array}{l}\text { International Review of } \\
\text { Administrative Sciences }\end{array}$ & $\begin{array}{l}\text { 4. Are we being served? A critical perspective on Canada's Citizens First } \\
\text { satisfaction surveys }\end{array}$ & 2010 \\
\hline \multirow[t]{2}{*}{ Public Administration Review } & $\begin{array}{l}\text { 5. The Future of the Study of Public Administration: Embedding Research Object } \\
\text { and Methodology in Epistemology and Ontology }\end{array}$ & 2011 \\
\hline & $\begin{array}{l}\text { 6. Repositioning American Public Administration? Citizen Estrangement, } \\
\text { Administrative Reform, and the Disarticulated State }\end{array}$ & 2013 \\
\hline \multirow[t]{2}{*}{ Public Administration } & 7. Women in UK Public Administration Scholarship? & 2011 \\
\hline & 8. Faith-Based Initiatives and The Challenges of Governance & 2011 \\
\hline $\begin{array}{l}\text { Public Administration and } \\
\text { Development }\end{array}$ & $\begin{array}{l}\text { 9. New Vistas for Development Management: Examining Radical-Reformist } \\
\text { Possibilities and Potential }\end{array}$ & 2010 \\
\hline
\end{tabular}

No primeiro artigo, encontrado na Web of Science, Raadschelders (2012) busca compreender quais fatores ou elementos contribuem para que um livro se torne influente no campo da administração pública. Questionam-se as duas listas apontadas como os grandes livros da administração pública apontando que outras obras importantes poderiam ser incluídas nesta lista (Sherwood, 1990). A crítica central de Raadschelders (2012) reside no fato destas listas não apresentarem obras de autores fora do eixo Estados Unidos e Europa, mantendo o paroquialismo da produção americana frente aos trabalhos de autores estrangeiros como a própria construção teórica de Alberto Guerreiro Ramos na América Latina. Também ressalta o aspecto ideológico de Kasdan (2012) ao apontar a obra de Osborne e
Gaebler (1994) entre os grandes livros da Administração Pública. De acordo com o autor, esta obra ganhou popularidade a partir da consolidação da visão neoliberal. Neste contexto, a produção acadêmica americana, sobretudo a de administração, torna-se endógena eliminando a possibilidade do diálogo com autores fora do eixo anglo-saxão e europeu. É importante manter diálogos com autores do eixo para a construção de uma percepção mais localizada dos fenômenos (Faria \& Meneghetti, 2010; Paes de Paula, 2013).

Em Ganapati (2012) é possível perceber como a localidade influencia a perspectiva de determinado conceito. $\mathrm{Na}$ administração pública o capital social tem recebido considerável atenção. No caso da cidade de Gölcük, o epicentro do 17 de agosto de 1999, 
terremoto na Turquia, a formação de capital social trouxe também desvantagens para a comunidade de mulheres afetada pelo desastre. Na perspectiva do autor, as redes de cidadãos ajudaram a perpetuar preconceitos baseados em gênero colocando mulheres em conflito com as autoridades estaduais. $O$ autor sugere algumas influências locais quanto ao capital social: a) no contexto turco é extremamente importante mencionar a necessidade de estudar a forma como o trabalho é dividido em relação ao gênero, para maior compreensão do capital social, pois, na Turquia a base da sociedade ainda é a patriarcal, no qual os estereótipos sobre o papel da mulher na sociedade continuam a existir; b) o capital social coloca as mulheres turcas em conflito com as autoridades estaduais.

$\mathrm{Na}$ visão de Farazmand (2012), existem cinco desafios fundamentais que marcarão a identidade do futuro da administração pública: a) globalização do capitalismo (que se torna cada vez mais predatória alinhando a crítica marxista). A globalização predatória e o capitalismo podem representar ameaças até mesmo mortais para à democracia, aos direitos humanos, o Estado, enfim, para a administração pública; b) fracasso das instituições governamentais e a ênfase no capitalismo de mercado. Para o autor isso é o resultado da cultura da privatização tornando instituições semipúblicas responsáveis por servir os interesses públicos - crítica muito alinhada à discussão presente na teoria crítica sobre a disseminação da ideologia gerencial e da racionalidade instrumental no contexto das organizações (Habermas, 1987; Paes de Paula, 2008; Faria, 2009). As instituições governamentais deixam de representar os interesses sociais arcando com o interesse do enclave do mercado; c) a visão empobrecida atual da administração pública como um empreendimento intelectual. Demonstra a necessidade de ampliar 0 entendimento da administração pública para uma maneira multicêntrica a que dialoga nas várias matrizes que permeiam o setor público como, por exemplo, o Estado, o Mercado e a Sociedade. Nessa conduta, observa-se a administração pública focando-se não somente no aparelho do estado (questão governamental/administrativa), mas também nas suas influências com outras instâncias que permeiam o contexto público; d) sucesso do próprio campo. Tanto no âmbito acadêmico e da prática profissional a administração pública tornouse $o$ foco do interesse de pessoas engajadas no campo. No discurso vemos o aperfeiçoamento da administração pública como um potencial futuro de uma nova governança entre Estado, Sociedade e Mercado; e) tecnologia (vista como uma espada de dois gumes). Se por um lado a tecnologia trouxe elementos substanciais para o aperfeiçoamento da administração pública (eGov, tecnologias da informação, agilidade, flexibilidade e transparência), por outro se configura como elemento de risco, pois cada vez mais as organizações públicas se veem presas na gaiola do discurso tecnológico, onde em grande parte do tempo torna-se empecilho para o desenvolvimento técnico, político e social do campo (Faria, 2009; Alcadipani \& Rosa, 2010).

Howard (2010) demonstra em sua pesquisa a preocupação com a ampla utilização de surveys no Canadá para medir o grau de satisfação dos cidadãos canadenses em relação à administração pública. Evidencia-se que os três principais problemas com este tipo de pesquisa se relacionam à falta de representatividade, a validade dos critérios causais e o tratamento de opiniões subjetivas. Essa crítica é lícita, segundo o autor, pois as surveys são construídas sobre um paradigma positivista amplamente influenciado pelas lógicas hegemônicas de conhecimento (racionalidade instrumental), que em uma análise mais profunda contribui para o fortalecimento e legitimidade dos enclaves do mercado (Adorno e Horkheimer, 1985; Mendonça, 2013).

Ao conceber as surveys pelo paradigma positivista (foco no cálculo utilitário das consequências) deixa-se de lado a importância de elementos que não podem ser quantificados em uma escala, e que confere relevância ao entendimento da satisfação dos canadenses em relação à administração pública (como por exemplo os valores cívicos, o entendimento do papel da cidadania, interesse público).

Raadschelders (2011) aponta que a administração pública tem passado por uma crise de identidade que tem refletido em dúvidas sobre a sua natureza e seu status na academia. Perguntas como a 'administração pública é uma ciência? Um ofício? Uma profissão? Uma arte?' podem representar, segundo o autor, uma negligência da literatura acadêmica por focar mais em questões empíricas do que em pressupostos ontológicos e epistemológicos. Embora a concentração de métodos estatísticos não seja tão forte na administração pública, há uma supervalorização inconfundível das ciências administrativas americanas ao tipo de conhecimento positivista. A necessidade de que os procedimentos metodológicos de pesquisa incorporem-se à epistemologia e ontologia de pesquisa (e não o contrário), desafio caro ao campo da epistemologia e ontologia, surge como possibilidade neste contexto. Destaca-se que a compreensão de habilidades relacionadas ao orçamento, avaliação de programas e gestão de recursos humanos devem ser complementadas com as perspectivas disciplinares sobre o civismo, o desenvolvimento do governo ao longo do tempo, as teorias políticas sobre a relação entre governo e sociedade.

Nas palavras do autor:

"Given that public administration is an art, a craft/profession, and a science, only interdisciplinarity can serve both generalist and specialist interests, on the one hand, and academician and practitioner interests, on the other hand. Public administration should focus as much on "real people who do real work" (Box 1992, 66) as the study does on analyzing data sets" (RAADSCHELDERS, 2011, p.922)

O sexto trabalho, de autoria de Durant e Ali (2013), faz uma análise crítica da ênfase do Estado administrativo na racionalidade técnico-jurídica empregada pelos estudiosos que veem no campo da gestão uma possibilidade para aplicação no setor público. $\mathrm{Na}$ concepção dos autores, a cultura do management contribui para que as informações no setor público tornem-se assimétricas em relação aos cidadãos e os seus representantes eleitos. Da mesma forma que um círculo vicioso, os especialistas, promovidos pelas técnicas de gestão, enquadram os problemas públicos como técnica, esquecendo-se de outras concepções, inclusive a política, marginalizando os cidadãos. Frente a esta problemática, os autores 
sugerem que os defensores da reforma administrativa, e os grandes segmentos do mainstream da administração pública, contribuem para a marginalização do papel deliberativo dos interesses dos cidadãos. Esta reflexão torna-se cada vez mais pertinente com a empresarização da administração pública, apontada por Farazmand (2012), como possibilidade clara de controle do mercado ou do management da vida social onde a racionalidade instrumental torna-se instrumento de opressão e controle da cidadania, ou seja, o capitalismo e a lógica do mercado 'prospera' (Boltanski \& Chiapello, 2009).

Essa ressignificação da organização pública para empresa pública, e do cidadão para o cliente, evidencia a prova que de fato esse fenômeno é um desafio importante, sob o ponto de vista da teoria crítica, pois representa uma tentativa de instrumentalização da própria administração pública (Habermas, 1987). Frente aos desafios citados, é importante ter em mente os olhares desta teoria que visa a garantia do éthos democrático e emancipatório dos indivíduos (Paes de Paula, 2008, Mendonça, 2013, Bertero et al., 2013).

Apesar de um dos objetivos da União Europeia (EU) ser a eliminação de desigualdades e promover a igualdade de gênero, na prática, a administração pública tende a valorizar a masculinidade. Esta conclusão foi evidenciada na pesquisa de Miller e Mctavish (2011). De acordo com as autoras, é possível encontrar a segregação e a discriminação em relação ao gênero no setor público no Reino Unido, sobretudo no contexto de concessão de bolsas de estudo. Para as autoras uma questão chave nesta temática é a medida no qual a academia de administração pública trata estas ambiguidades aparentes, quando se contrasta os discursos presentes na política da EU com as práticas reais. No contexto do Reino Unido isso tem uma relevância social importante dado aos cortes educacionais no período atual. Neste sentido, Miller e Mctavish (2011) propõem a estimulação de enquadramentos teóricos que reflitam criticamente as relações de gênero no currículo da administração pública.

Na pesquisa foram encontrados temas não tão discutidos como nos trabalho de Biecricher (2011) e Guljarani (2010). Biebricher (2011) analisa a criação do Escritório de Iniciativas Comunitárias e Religiosas, nos Estados Unidos, e sua influência na recuperação de dependentes. No programa enfatiza-se a forma como os discursos e as tradições moldaram a criação deste novo arranjo de governança, especificamente nas políticas públicas sociais. Os princípios norteadores baseiam-se no diálogo com as diversas crenças dos atores envolvidos no processo. Apesar de ter importantes avanços, um dos problemas que limitam o projeto é a própria divergência de opiniões entre os tomadores de decisão. Neste sentido, torna-se como elementos de equilíbrio, ou até mesmo instrumentos de cooptação psicológica, os discursos implementados pelo programa que por hora são orientados pelos princípios da escolha pública e do comunitarismo.

Guljarani (2010) evidencia a temática do desenvolvimento. Segundo a autora, as abordagens contemporâneas inspiradas por uma vertente mais crítica, buscam descontruir o discurso do progresso baseado em pressupostos tecnicistas, como aqueles advindos da vertente reformista. Na perspectiva mais radical, os autores que vão discutir o desenvolvimento defendem a dissolução das arquiteturas de progresso em favor daqueles que celebram novas formas de planejar o avanço econômico como os movimentos sociais. Além disso, partem do pressuposto de que o progresso baseado nas perspectivas reformistas (em que se dá ênfase nos aparatos de gestão) torna-se pernicioso com a realidade de países de terceiro mundo. Sugere-se que os estudos sobre gestão de desenvolvimento podem e devem se preocupar com a possibilidade de se ter um avanço não gerencial, estabelecendo uma ligação entre a perspectiva mais radical (crítica) e a dos reformistas. Argumenta-se que 0 futuro da gestão de desenvolvimento pode e deve ser radicalmente reformista, ou seja, a autora procura minimizar as dicotomias existentes entre as duas vertentes, e buscar as contribuições de cada uma (Guljarani, 2010). Após a análise dos trabalhos presentes na Web of Science observou-se que a maioria das pesquisas vai de encontro com pressupostos hegemônicos estabelecidos pelo maistream da administração. Sobretudo, no que tange à centralidade da gestão e do tecnicismo, os pesquisadores buscam alternativas de análise para interpretar a administração por um viés mais crítico. Após as análise dos nove artigos selecionados na base Web of Science, evidencia-se, no quadro 2 , os artigos que foram provenientes da base Scopus.

Quadro 2: Artigos selecionados na Scopus

\begin{tabular}{|c|c|c|}
\hline Periódico & Títulos & Ano \\
\hline $\begin{array}{l}\text { Canadian Journal of } \\
\text { Administrative Sciences }\end{array}$ & $\begin{array}{l}\text { 1. Administrative Reforms and Global Managerialism: A Critical Analysis of Three } \\
\text { Brazilian State Reforms }\end{array}$ & 2010 \\
\hline \multirow[t]{2}{*}{$\begin{array}{l}\text { Critical Perspectives on } \\
\text { Accounting }\end{array}$} & $\begin{array}{l}\text { 2. Profiting from destruction: The Iraq reconstrution, auditing and the } \\
\text { management of fraud }\end{array}$ & 2013 \\
\hline & $\begin{array}{l}\text { 3. Critical Accounting and communicative action: On the limits of consensual } \\
\text { deliberation }\end{array}$ & 2013 \\
\hline \multirow[t]{2}{*}{ Management in Education } & 4. The retreat of the state and the future of social science & 2014 \\
\hline & $\begin{array}{l}\text { 5. Critical friendship and critical orphanship: Embedded research of an English } \\
\text { local authority initiative }\end{array}$ & 2014 \\
\hline
\end{tabular}

Fonte: Resultados da pesquisa.

No primeiro trabalho selecionado da base Scopus Imasato, Martins e Pieranti (2011) realizam uma análise crítica do contexto global das reformas gerenciais. Para os autores as reformas implementadas no final do século XX e início do século XXI, no
Brasil, foram bastante influenciadas pela corrente da New Public Management (NPM). Para chegar a essas conclusões, os autores realizaram uma análise comparativa das implicações administrativas, sociais e políticas das reformas do executivo de 
três estados do Brasil: Maranhão, Minas Gerais e Santa Catarina. A filosofia da NPM foi adotada para promover a noção gerencial no contexto regional - muito cara à ideologia neoliberal presente no mainstream da administração (Paes de Paula, 2008).

As variáveis de eficiência, gerencialismo e organização estrutural obteve mais ênfase no período em que aconteceram estas reformas enquanto variáveis, relacionadas à participação social, e também que colocavam no centro o papel da sociedade na coprodução de políticas públicas como a prestação de contas e a participação democrática obteve menor atenção no desenvolvimento dessas reformas.

A dinâmica do gerencialismo, segundo os autores, corroborando com as perspectivas apontadas por Paes de Paula et al., (2009) tende a minimizar os apelos sociais e políticos no âmbito da gestão pública, o que, por sua vez, coloca o tecnicismo presente na NPM no centro do debate. Os discursos, as ideias, as políticas e as práticas organizacionais são voltados para o entrelaçamento entre interesses públicos e privados. A gestão torna-se um mito a ser alcançado, pois tenta-se incorporar na administração pública os instrumentos presentes na gestão empresarial sem a devida adaptação (Ramos, 1989). Sugere-se, então, que o gerencialismo representa um risco para as instituições democráticas, uma vez que distrai os membros das organizações públicas e governos de seu papel mais tradicional que é a busca pelo bem comum. As reformas administrativas dos três estados brasileiros estudados estão ligadas à disseminação do gerencialismo nos governos e organizações públicas no Brasil.

Imasato, Martins e Pieranti (2011) evidenciam que, na análise dos três casos, as reformas administrativas extrapolam as necessidades locais, pois sofrem pressões inclusive das tendências internacionais e nacionais para sua implementação - forças da instrumentalização das organizações por meio de uma racionalidade técnica e focada em resultados (Habermas, 1987).

O segundo trabalho dessa base, de autoria de Chwastiak (2013), analisa o papel do governo norte americano no esforço de reconstrução do Iraque. Ela aponta que a agenda liberal implantada pelo governo Bush tem favorecido empresas norte americanas, enquanto os contribuintes norte americanos e a população iraquiana têm sido fraudados. Especificamente no Iraque, a política neoliberal dos EUA tem gerado um ambiente corrupto e sem lei. Como resultados as empresas colhem lucros enormes através de fraudes e, uma das causas destas fraudes, segundo o texto, é a forma como os relatórios de auditoria são produzidos pelo Office of the Special Inspector General for Iraq Reconstruction (SIGIR).

O governo Bush, segundo a autora, tem criado uma espécie de paraíso capitalista (o governo estaria garantindo que os lucros empresariais estariam protegidos da concorrência, fiscalização) para empresas norte-americanas e britânicas que trabalham na reconstrução do Iraque que, por sua vez, sofreu influências monopolistas criando um ambiente anárquico, praticamente sem regras, enriquecendo-se à custa de todos os outros (contribuintes norte-americanos e iraquianos). No centro desta problemática encontra-se o SIGIR, que é alertado pela autora de mascarar os dados auditados e por tornar a corrupção mais institucionalizada. Chwastiak (2013) recorre a teóricos como Naomi Klein (2008) que evidencia como a Shock Doctrine tem sido a impulsionadora do capitalismo predatório estadunidense. $E$ isso se alinha muito com a crítica à hegemonia dos EUA, em termos de relações internacionais, e também em termos de políticas econômicas (Adorno \& Horkheimer, 1985, Paes de Paula et al., 2009).

Brown e Dillard (2013) têm como objetivo ampliar o debate sobre a contabilidade crítica, desenvolvida por Richard Laughlin, pelo diálogo entre os parâmetros da ação comunicativa e democracia deliberativa de Jürgen Habermas, com a democracia agonística de Chantal Mouffe. Os autores argumentam que a democracia deliberativa se configura apenas uma das várias bases democráticas úteis para compreender ou melhorar os sistemas de contabilidade e prestação de contas contemporâneas. Além disso, alegam que ao apoiar-se no conceito de democracia deliberativa habermasiana, a contabilidade crítica de Laughlin deixa de considerar as dimensões de desacordo e diferença entre as interações democráticas. É justamente neste ponto que reside a contribuição de Chantal Mouffe. Esta parte do princípio que as opiniões divergentes devem ser valorizadas e que a base, para se ter uma democracia, está no dissenso e no pluralismo de opiniões.

Esta conceituação se afasta da concepção habermasiana que vê na diversidade de posicionamento e no conflito um obstáculo a ser superado para termos uma democracia. Nesta discussão, Brown e Dillard (2013), baseados em pressupostos da democracia agonística, em estudos dos campos de planejamento comunicativo e análise de política crítica, argumentam que as abordagens da democracia deliberativa precisam ser equilibradas com teorizações que reconhecem a realidade e valor de lutas mais abertas. No que tange à contabilidade crítica, os autores mencionam que há algo de errado com as correntes dominantes da contabilidade. Também criticam o ambiente tecnocrático que tem permeado a profissão contábil, no qual os valores têm sido relacionados ao aspecto normativo, o que tem levado uma baixa reflexividades por parte da contabilidade tradicional dos efeitos prejudiciais das relações de poder em contextos organizacionais e sociais, especialmente no contexto neoliberal.

Baars (2014) contribui para o debate em questão por oferecer reflexões sobre como a condução de embedded research podem contribuir para a garantia do futuro das ciências sociais no contexto britânico. Em meio ao descrédito (cortes profundos nos gastos públicos) do governo para o subsídio de ciências sociais no ensino superior e sobre as comunidades locais, o autor propõe as embedded research como um dos itens de uma agenda pública renovada para legitimar as atividades da ciência social. Em outras palavras, a retirada de investimento do Estado Britânico sobre as ciências sociais é um dos possíveis reflexos de uma crise mais ampla de compromisso do Estado com este campo. Além disso, evidenciam-se algumas experiências de condução de pesquisa integrada entre pesquisador e comunidade, mostrando que este tipo de abordagem de pesquisa tem o potencial de produzir conhecimento e benefícios práticos para os pesquisadores e 
sociedade em geral, oferecendo uma oportunidade de troca de saberes e, como consequência disso, a criação de valor (no sentido de enriquecimento social, do saber e coletivo), tanto para a comunidade e pesquisadores (Baars, 2014).

Sob uma aplicação prática, no trabalho de Duggan (2014), evidencia-se que este tipo de pesquisa (embedded research) tem sido cada vez mais comum, em nível de doutorado, na Inglaterra. As rápidas e amplas reformas do setor público inglês tem motivado este tipo de pesquisa, pois se apresentam como um aspecto desafiador e pouco explorado para pesquisadores que utilizam deste tipo de metodologia, sobretudo pelo fato do estudante, como pesquisador embebido no contexto organizacional, ter certa liberdade para negociações para o desenvolvimento prático e teórico de seus estudos de doutorado (Duggan, 2014).

Após as análises realizadas sobre os artigos encontrados na base de dados Scopus, em seguida analisam-se aqueles provenientes da base Scielo. A relação destes trabalhos pode ser verificada no quadro 3

Quadro 3: Artigos selecionados na Scielo

\begin{tabular}{|c|c|c|}
\hline Periódico & Títulos & Ano \\
\hline \multirow{7}{*}{$\begin{array}{l}\text { Revista de Administração } \\
\text { Pública }\end{array}$} & 1. A gestão de recursos humanos em uma instituição pública brasileira de ciência e tecnologia em saúde: o caso Fiocruz & 2010 \\
\hline & $\begin{array}{l}\text { 2. Uma revisão crítica sobre cidades e mudança climática: vinho velho em garrafa nova ou um novo paradigma de ação } \\
\text { para a governança local? }\end{array}$ & 2011 \\
\hline & 3. Poder simbólico no reajuste tarifário do transporte metropolitano de passageiros de Porto Alegre na crise de 2004 & 2011 \\
\hline & $\begin{array}{l}\text { 4. Public hearings as a tool to improve participation in regulatory policies: case study of the National Agency of Electric } \\
\text { Energy }\end{array}$ & 2013 \\
\hline & $\begin{array}{l}\text { 5. Políticas compensatórias versus emancipatórias: desafios para implementação de programas de geração de renda } \\
\text { às famílias em situação de risco }\end{array}$ & 2012 \\
\hline & 6. Memória e formalização social do passado nas organizações & 2011 \\
\hline & 7. Representações do eleitor: revendo teorias e propondo novos caminhos & 2012 \\
\hline
\end{tabular}

Fonte: Resultados da pesquisa

O trabalho de Mello e Filho (2010) relata a experiência realizada para avaliar a gestão de recursos humanos na Fundação Oswaldo Cruz (instituição pública de ciência e tecnologia de saúde e que ocupa uma posição estratégica no Sistema Único de Saúde brasileiro - SUS). Os autores destacam as transformações ocorridas no sistema capitalista que alteraram e influenciaram a sociedade ocidental, e que ocasionaram mudanças profundas na gestão de recursos humanos. Os autores relatam ainda uma dissonância entre o discurso idealizado pelos aspectos teóricos e a prática adotada, visto que no campo discursivo a organização refere-se a uma gestão estratégica de pessoas, porém na prática observa-se uma predominância de atividades tradicionais e operacionais características do paradigma 'departamento de administração de pessoal'.

Sob o ponto de vista da implementação de políticas públicas locais, Martins e Ferreira (2011), destacam a relevância desse processo como elemento fundamental para lidar com os problemas relacionados aos impactos das mudanças climáticas nas cidades. Os impactos negativos da mudança climática, apontados pelos autores, afetarão os recursos hídricos, disponibilidade de tratamento de água e esgoto, produção de alimentos, sistema de transporte e mobilidade humana, saúde humana, energia, moradia, entre outros. Destarte, as cidades seriam o ponto de tensão desses impactos e que constantemente vivem sobre a relação de vulnerabilidade versus responsabilidade, portanto, os governos locais seriam os mais adequados para realizar e empreender ações de mitigação e adaptação a esses problemas. Os autores destacam que as medidas a serem realizadas pelos governos locais trata-se de processos de aprendizagem local, e dependem de conhecimentos e metodologias de ações, não somente de vontade política e de recursos financeiros, em busca da transformação das cidades brasileiras para um futuro mais sustentável.

O exercício nos discursos pronunciados na elaboração dos estudos de reajuste tarifário do transporte metropolitano de passageiros de Porto Alegre foi abordado no trabalho assinado por Filho (2010). Durante o processo de reajuste das tarifas ocorreu uma grande tensão entre os interesses públicos e os privados, em que os atores sociais mobilizaram-se em torno de seus interesses. Suas ações se expressaram em argumentações matemáticas pela exposição de planilhas de cálculos das tarifas. Em vistas disso, de acordo com o autor, os discursos utilizaram a condensação temática para incluir no processo de produção social somente aqueles que possuem conhecimento sobre o processo cálculos dos custos operacionais e de produção dos serviços de transporte, valorizando uma racionalidade instrumentalizada e tecnicista que exclui a participação ampla e efetiva (Habermas, 1987; Ramos, 1989). Visto que utilizaram a formalização matemática em todo o processo, as vozes daqueles grupos sociais, que não possuíam tal conhecimento, não foram ouvidas, em específico, por falta de capital simbólico e cultural, fazendo que os discursos dos usuários dos transportes públicos não fossem considerados na elaboração dos novos reajustes.

$\mathrm{Na}$ pesquisa de Castro (2013), discute-se a temática da participação dos cidadãos em políticas públicas, por meio do estudo na Agência Nacional de Energia Elétrica brasileira (Aneel), especificamente sobre audiências públicas que tiverem o tema da revisão tarifária. O ponto central do artigo é o dilema entre cidadãos leigos na discussão de políticas públicas, em específico. A autora afirma que, temas mais controversos e "maus", como revisão tarifária, atraem mais o público leigo, porém, nas audiências 
estudadas, em sua maioria, possuíram a participação de agentes reguladores, ao passo que os representantes dos consumidores não possuem capacitação suficiente para lidar com questões complexas.

Outra questão abordada é a utilização indevida de audiências públicas para promover uma arena eleitoral, aumentando, deste modo, os conflitos e dificultando o aumento de conscientização da população por meio de discussões. Na visão da autora as audiências públicas, apesar de ser parte importante, não podem ser consideradas como solução final quando se trata de participação do cidadão, por isso devem ser utilizados em paralelo a outras metodologias e mecanismos que visem à transformação da participação formal em participação prática, bem como ressalta a necessidade dos representantes dos consumidores/cidadãos buscarem mais capacitação para tratar de questões complexas em audiências públicas.

Sartori e Garcia (2012) analisam famílias pertencentes ao Programa de Erradicação do Trabalho infantil, na cidade de Campinas. Os autores discutiram a relação entre políticas emancipatórias e compensatórias e os desafios da implementação de programas de geração de renda às famílias em situação de risco. A grande crítica do artigo é que, apesar dos programas sociais de vieses compensatórios (como o caso do Programa de Erradicação do Trabalho Infantil - Peti) trazerem diversas contribuições às famílias, não proporcionam autonomia para as mesmas, bem como criam uma dependência permanente, o que pode afetar as futuras gerações. Em contrapartida, os autores sugerem a adoção de medidas emancipatórias que integrem os membros adultos pertencentes a estas famílias, com finalidade de retirá-las do círculo de assistencial social. Deve-se ressaltar que esta perspectiva alinha-se a contribuição central da Teoria Crítica frankfurtiana aos estudos organizacionais (Adorno \& Horkheimer, 1985; Paes de Paula, 2008).

Na pesquisa de Costa e Saraiva (2011) foi feita uma discussão sobre a memória, no que diz respeito à história empresarial, e a formalização social do passado das organizações. Os autores argumentam que o resgate do passado empresarial não é neutro, e esse processo não consiste somente em uma mera ilustração cronológica dos acontecimentos anteriores, mas sim torna possível a coesão e a definição de papéis dos diversos grupos da organização por meio das interpretações feitas acerca desse passado.

A construção da história empresarial perpassa a intenção deliberada de que o passado pareça ser o mais objetivo e "limpo" possível, e essas intenções, conforme afirmam Costa e Saraiva (2011), objetivam compor uma história sem manchas, sem humanidade, que esvaziam o sentido propriamente social dos relatos, bem como silenciam aspectos típicos das construções humanas, como enganos, divergências e mentiras. O ponto crítico deste trabalho aponta que a história se torna um campo de enfrentamento ideológico dentro do grande campo de embates entre capital e trabalho, no qual os trabalhadores destituídos dos meios de construir uma história material utilizam-se da história oral, que funciona como instância de resistência a ações e projetos que utilizam como base de controle o passado. Os autores finalizam o artigo ressaltando que os estudos organizacionais devem permitir que aqueles que não têm voz (ou que pouco podem manifestar) contem suas histórias.

Barros, Sauerbronn e Ayrosa (2012) analisaram criticamente o marketing político e o comportamento do eleitor em relação ao voto, e constataram que o comportamento do eleitor é pouco estudado. Ressaltam que, especificamente no Brasil, a produção científica sobre as escolhas político-eleitorais ainda é muito pequena, e que os poucos estudos existentes no campo de administração possuem foco no marketing e orientação gerencial. Esses estudos, de cunho tradicional, partem da premissa de que o eleitor ocupa uma posição de "subracionalidade", na qual as campanhas políticas representam um grande papel na escolha dos candidatos, visto que os eleitores não teriam memória de decisões passadas, e nem mesmo demonstram possibilidade de satisfação com os resultados dos processos eleitorais. Nessa mesma perspectiva, em que o marketing seria fundamental para a escolha do eleitor, o candidato é concebido como um "produto", que deve ser administrado pelo setor de marketing, que decide seu "posicionamento" e embalagem, com objetivo final de "venda". Conforme destacado pelos autores, na visão do marketing, o consumo seria a atribuição de significados e também é uma forma de expressão, sendo assim, a expressão do comportamento do eleitor é o consumo político, contudo destacam que o voto também pode ser compreendido como ação social, em face disso deveria a agenda de pesquisa que contemple o comportamento do eleitor deveria aumentar, pois é um tema que possui grande importância na sociedade.

No trabalho, Reis e Neto (2013) evidencia-se um estudo sobre tráfico de seres humanos e trabalho forçado, no qual analisaram o fluxo de informações utilizado pela Organização Internacional do Trabalho (OIT). Os autores discutiram as Conversões no 29 e nํㅜ 105 da OIT que tratam respectivamente da definição de trabalho forçado e da abolição destes, eles averiguaram nesta análise que os países assumem uma postura indesejável quanto ao envio de informações para a OIT no cumprimento dessas convenções. Os autores evidenciaram que a ausência de tratamento trabalhista quanto ao tráfico de pessoas, a inexatidão conceitual adotada pelos países quanto ao tráfico humano, e mesmo aqueles que adotam a definição do Protocolo de Palermo (referente ao combate do tráfico humano) ainda encontram espaços para diversas interpretações. Os autores criticaram a questão do tráfico de pessoas não possuir uma legislação específica, sendo associado diretamente ao trabalho forçado, o que necessariamente não acontecem juntos, pois podem existir situações de trabalho forçado sem que os trabalhadores tenham sido traficados.

A grande crítica deste artigo consiste na exploração humana, que se torna mais capitalizada, refinada e globalizada ao passo que adota a lógica mercadológica inerente ao sistema capitalista, e na imprecisão conceitual que repercute e inúmeros problemas quanto à divulgação de informações sobre tráfico humano, acarretando uma abordagem incompleta do problema, dificultando assim um 
tratamento descente e de tutela dos direitos humanos a essas vítimas. Não se pode negar que todas estas temáticas são debatidas e discutidas de uma maneira mais aprofundada pelas lentes da teoria crítica (Mendonça, 2013). Eis a oportunidade de uma análise mais profícua na administração pública.

\section{Considerações finais}

Os trabalhos analisados nas três bases sugerem temas diversos, mostrando que as pesquisas que constroem a administração pública, por meio de uma epistemologia mais livre e multicêntrica como a teoria crítica, conseguem refletir sobre temas que não se fazem tão presentes no cotidiano de perspectivas mais positivistas (ver Filho, 2010; Miller e Mctavish, 2011; Reis \& Neto, 2013; Chwastiak, 2013; Baars, 2014). Dessa forma, foi possível observar a predominância das críticas ao modelo político implementado por países de todo o mundo, com o neoliberalismo através de reformas gerenciais (Imasato, Martins e Pieranti, 2011), pelo paroquialismo anglo-saxão e europeu (Raadschelders, 2012), pelo perigo da aproximação entre gestão pública e privada através da incorporação da lógica de mercado, da cultura do management e dos instrumentos da gestão privada à administração pública (Howard, 2010; Farazmand, 2012; Durant \& Ali, 2013), preocupação com os governos locais (Martins \& Ferreira, 2011), preocupação com a influência do poder simbólico para perpetuação do tecnicismo (Filho, 2010).

Alguns artigos também analisaram a participação dos cidadãos em políticas públicas (Castro, 2013, Sartori \& Garcia, 2012), uma visão crítica sobre o marketing político (Barros, Sauerbronn e Ayrosa, 2012), gênero (Miller \& Mctavish, 2011), tráfico de seres humanos (Reis \& Neto, 2013), capital social (Ganapati, 20120, corrupção (Chwaaski, 2013) e a importância das embedded researchs (Baars, 2014; Duggan, 2014). No quadro 4 é possível observar a ideia central de todos os trabalhos analisados.

Quadro 4: Debates centrais estabelecidos nos artigos selecionados para pesquisa

\begin{tabular}{|c|c|c|}
\hline Artigo & Título & Debate Central \\
\hline 1 & What Are "Great Books" in the Study of Public Administration? Some Polemic Thoughts About the Surveys of Sherwood and Kasdan & $\begin{array}{l}\text { Fatores que determinam a } \\
\text { importância de uma obra no } \\
\text { contexto da administração pública }\end{array}$ \\
\hline 2 & Downsides of Social Capital for Women During Disaster Recovery: Toward a More Critical Approach & $\begin{array}{l}\text { Capital Social e conflitos de } \\
\text { gênero }\end{array}$ \\
\hline 3 & The Future of Public Administration: Challenges and Opportunities-A Critical Perspective & $\begin{array}{l}\text { Desafios essenciais para o futuro } \\
\text { da Administração Pública }\end{array}$ \\
\hline 4 & Are we being served? A critical perspective on Canada's Citizens First satisfaction surveys & $\begin{array}{l}\text { Ampla utilização de Surveys no } \\
\text { setor público no Canadá }\end{array}$ \\
\hline 5 & The Future of the Study of Public Administration: Embedding Research Object and Methodology in Epistemology and Ontology & $\begin{array}{l}\text { Crise de Identidade da Academia } \\
\text { em Administração Pública }\end{array}$ \\
\hline 6 & Repositioning American Public Administration? Citizen Estrangement, Administrative Reform, and the Disarticulated State & $\begin{array}{l}\text { Cultura do Management e suas } \\
\text { influências contraditórias no Setor } \\
\text { Público }\end{array}$ \\
\hline 7 & Women in UK Public Administration Scholarship? & $\begin{array}{l}\text { Gênero e Segregação no contexto } \\
\text { Educacional no Reino Unido }\end{array}$ \\
\hline 8 & Faith-Based Initiatives and The Challenges of Governance & $\begin{array}{l}\text { Política de Recuperação de } \\
\text { Dependentes }\end{array}$ \\
\hline 9 & New Vistas for Development Management: Examining Radical-Reformist Possibilities and Potential & $\begin{array}{l}\text { Abordagens sobre } 0 \\
\text { Desenvolvimento }\end{array}$ \\
\hline 10 & Administrative Reforms and Global Managerialism: A Critical Analysis of Three Brazilian State Reforms & $\begin{array}{l}\text { Crítica ao contexto global de } \\
\text { reformas administrativas }\end{array}$ \\
\hline 11 & Profiting from destruction: The Iraq reconstrution, auditing and the management of fraud & $\begin{array}{l}\text { A política Neoliberal dos EUA e } \\
\text { seu impacto no contexto do Iraque }\end{array}$ \\
\hline 12 & Critical Accounting and communicative action: On the limits of consensual deliberation & $\begin{array}{l}\text { Contabilidade Crítica e o debate } \\
\text { democrático }\end{array}$ \\
\hline 13 & The retreat of the state and the future of social science & $\begin{array}{l}\text { Condução de Embedded } \\
\text { Research }\end{array}$ \\
\hline 14 & Critical friendship and critical orphanship: Embedded research of an English local authority initiative & $\begin{array}{l}\text { Aplciação de Embedded Research } \\
\text { no contexto Britânico como } \\
\text { alternativa frente aos cortes } \\
\text { governamentais }\end{array}$ \\
\hline 15 & A gestão de recursos humanos em uma instituição pública brasileira de ciência e tecnologia em saúde: o caso Fiocruz & $\begin{array}{l}\text { Gestão de Recursos Humanos no } \\
\text { Setor Público }\end{array}$ \\
\hline 16 & $\begin{array}{l}\text { Uma revisão crítica sobre cidades e mudança climática: vinho velho em garrafa nova ou um novo paradigma de ação para a } \\
\text { governança local? }\end{array}$ & $\begin{array}{l}\text { Políticas Públicas Locais e } \\
\text { Impactos nas Mudanças climáticas } \\
\text { nas cidades }\end{array}$ \\
\hline 17 & Poder simbólico no reajuste tarifário do transporte metropolitano de passageiros de Porto Alegre na crise de 2004 & Discurso e Capital Simbólico \\
\hline 18 & Public hearings as a tool to improve participation in regulatory policies: case study of the National Agency of Electric Energy & $\begin{array}{l}\text { Participação Social nas Políticas } \\
\text { Públicas }\end{array}$ \\
\hline 19 & $\begin{array}{l}\text { Políticas compensatórias versus emancipatórias: desafios para implementação de programas de geração de renda às famílias em } \\
\text { situação de risco }\end{array}$ & $\begin{array}{l}\text { Políticas Emancipatórias e } \\
\text { Políticas Compensatórias }\end{array}$ \\
\hline 20 & Memória e formalização social do passado nas organizações & $\begin{array}{l}\text { História Organizacional, } \\
\text { enfrentamento ideológico entre } \\
\text { capital e trabalho }\end{array}$ \\
\hline 21 & Representações do eleitor: revendo teorias e propondo novos caminhos & $\begin{array}{l}\text { Marketing Político e } \\
\text { Comportamento do eleitor }\end{array}$ \\
\hline 22 & $\begin{array}{l}\text { Tráfico de seres humanos e trabalho forçado: uma abordagem crítica ao fluxo de informações utilizado pela Organização Internacional } \\
\text { do Trabalho }\end{array}$ & $\begin{array}{l}\text { Tráfico de seres humanos e } \\
\text { trabalho forçado }\end{array}$ \\
\hline
\end{tabular}

Fonte: Resultados da pesquisa

Além disso, foi possível observar que os autores dos artigos pesquisados também se preocupam com o futuro da administração pública. A análise do futuro deste campo não desconsidera 0 presente atual, conforme análise de Raadchelders (2011). Existe uma preocupação com a maneira como os trabalhos neste campo têm sido construídos, como já aponta o estudo realizado por Fadul, Silva, e Silva (2012).
Desse modo, o futuro da administração pública deve estar atrelado a maior reflexividade e preocupação com a construção de teorias que valorizem a emancipação dos indivíduos, a práxis, o olhar para a localidade, a preocupação com assuntos interdisciplinares e a mudança do eixo para olhar a realidade de países, até mesmo periféricos. A teoria crítica tem grande contribuição para o campo. Importante salientar que nos trabalhos 
selecionados encontrou-se a presença de autores como Foucault, Habermas, Mouffe, Bourdieu. No entanto, a maioria dos trabalhos analisados não utilizaram de forma central os conceitos destes autores (considerados como autores das abordagens críticas).

Este estudo corrobora com Box (2005) ao evidenciar a baixa utilização da teoria crítica nos estudos de administração pública. Apesar disso, os trabalhos analisados apresentaram uma perspectiva crítica nos moldes de Sousa Santos (1999), buscando retratar a realidade não como ela é, mas buscando uma reflexão sobre aquilo que está oculto e que não se consegue olhar sem uma lente bem calibrada e com o grau necessário. Por trazer estas reflexões, evidencia-se que este trabalho contribui para ampliar o debate sobre as interlocuções entre teoria crítica e administração pública apontando para possibilidades e tendências de estudos neste campo. Cabe a estudos futuros investigar por que a teoria crítica, apesar de ser um referencial que busca uma análise mais profunda dos bastidores das organizações e até mesmo das problemáticas que circundam a sociedade, não tem sido uma lente para olhar as problemáticas na administração pública. Será que a falta de trabalhos que utilizam destes referenciais demonstram certa cautela dos pesquisadores para analisar as mazelas sociais, ou podem ter outros significados? Acredita-se que, por suas características, a teoria crítica poderia contribuir bastante para a compreensão de tais problemáticas.

Conclui-se, portanto, dado as problemáticas presenciadas pelas organizações e sociedade, que a utilização de referenciais da teoria crítica pode ser uma boa oportunidade para reflexão e para firmar o compromisso da administração pública em dar significados ao conhecimento que tem sido produzido por este campo. A emancipação surge, então, como categoria fundamental para os pesquisadores do campo de administração pública como propulsora de uma razão crítica que busca contestar a realidade e a dominação naturalizada, através da dialética da realidade presente. Coloca-se em destaque aquelas metodologias que valorizem a experiência local, a interlocução entre teoria e prática e a possibilidade de construção da pesquisa de forma integrada entre comunidade e pesquisador.

\section{Referências}

Adler, P. S., Forbes, L. C., \& Wilmott, H. (2007). Critical Management Studies. Taylor e Francis Group, LLC.

Adorno, T. W., \& Horkheimer, M. (2006). Dialética do Esclarecimento: fragmentos filosóficos. Rio de Janeiro: Zahar.

Alcadipani, R., \& Rosa, A. R. (2010). O pesquisador como o outro: uma leitura pós-colonial do "Borat" Brasileiro. Revista de administração empresas, v. 50, n.4, pp. 371-382.

Alcadipani, R., \& Tureta, C. (2009). Perspectivas críticas no Brasil: entre a "verdadeira crítica" e o dia a dia. Cadernos EBAPE. BR, v. 7, no 3, artigo 7.

Andion, C. (2012). Por uma Nova Interpretação das Mudanças de Paradigma na Administração Pública. Cadernos EBAPE.BR, 10 (1), 1-19.

Baars, S. (2014). The retreat of the state and the future of social Science. Management in Education, Vol 28(1) 6-11.

Barros, D. F., Sauerbronn, J. F. R., \& Ayrosa, E. A. T. (2012). Representações do eleitor: revendo teorias e propondo novos caminhos. Revista de Administração Pública, 46 (2): 477-91.

Barroso, J., Gollop, C. J., Sandelowski, M., Meynell, J., Pearce, P. F., \& COLLINS, L. J. (2003). The Challenges of Searching for and Retrieving Qualitative Studies, West J Nurs Res, 25: 153.

Berwanger, O., Suzumura, E. A., Buehler, A. M., \& Oliveira, J. B. (2007) Como Avaliar Criticamente Revisões Sistemáticas e Metanálises? Revista Brasileira de Terapia Intensiva, Vol. 19 № 4, Outubro-Dezembro.
Bertero, C., Alcadipani, R., Cabral, S., Faria, A., \& Rossoni, L. (2013). Os Desafios da Produção do Conhecimento em Administração no Brasil. Cadernos EBAPE.BR, v. 11, pp. 181-196.

Biebricher, T. (2011). Faith-Based Initiatives and the Challenges of Governance. Public Administration Vol. 89, No. 3, (1001-1014).

Boltanskil, L., \& Chiapello, E. (2009). O novo espírito do capitalismo, São Paulo: Martins Fontes.

Boava, D. L. T., \& Macedo, F. M. F. (2011). Contribuições da fenomenologia para os estudos organizacionais. Cadernos EBAPE.BR, v.9, Edição Especial, artigo 2, Rio de Janeiro, jul.

Box, R. C. (2005). Critical Social Theory in Public Administration. Armonk, New York, M. E. Sharpe.

Brown, J., \& Dillard, J. (2013). Critical Accounting and communicative action: On the limits of consensual deliberation. Critical Perspectives on Accounting, 24: 176-190.

Burrel, G., \& Morgan, G. (1979). Sociological paradigms and organizational analysis. London: Heinemann.

Camisón-Zornoza, C., Lapiedra-Acamí, R., Segarra-Ciprés, M., \& BoronatNavarro, M. (2004). A Meta-analysis of Innovation and Organizational Size, Organization Studies, 25: 331.

Castro, C. M. (2013). Public hearings as a tool to improve participation in regulatory policies: case study of the National Agency of Electric Energy. Revista de administração Pública, 47: 1069-87, 2013.

Chwastiak, M. (2013). Profiting from destruction: The Iraq reconstrution, auditing and the management of fraud. Critical Perspectives on Accounting, 24: 32-43.

Costa, A. S. M., \& Saraiva, L. A. S. (2011). Memória e formalização social do passado nas organizações. Revista de Administração Pública, 45 (6): 1761-80.

Deetz, S. (1996). Describing Differences in Approaches to Organization Science: Rethinking Burrell and Morgan and Their Legacy. Organization Science, Vol. 7, No. 2, March-April.

Domingues, J. M. (1999). Criatividade Social, Subjetividade Coletiva e a Modernidade Brasileira Contemporânea. Rio de Janeiro, Contra Capa.

Domingues, J. M. (2011). Vicissitudes e possibilidades da teoria crítica hoje. Sociologia e Antropologia, v.01.01: 71-89.

Duggan, J. R. (2014). Critical friendship and critical orphanship: Embedded research of an English local authority initiative. Management in Education, Vol 28(1) 12-18.

Durant, R. F., \& Ali. S. B. (2012). Repositioning American Public Administration? Citizen Estrangement, Administrative Reform, and the Disarticulated State. Public Administration Review, Vol. 73, Iss. 2, pp. 278-289.

Fadul, E. M. C., Silva, M. de A.M. da, \& Silva, L. P. da. (2012). Ensaiando interpretações e estratégias para o campo da administração pública no Brasil. Revista de Administração Pública, Rio de Janeiro, v. 46, n. 6, Dec.

Farazmand, A. (2012). The Future of Public Administration: Challenges and Opportunities-A Critical Perspective. Administration \& Society 44(4) $487-517$.

Faria, J. H. de. (2009). Teoria Crítica em estudos organizacionais no Brasil: 0 estado da arte. Cademos EBAPE. BR, v. 7, n³, artigo 8, Rio de Janeiro, Set.

Faria, J. H. de. (2012). Dimensões da Matriz Epistemológica em Estudos em Administração: uma proposição. In: Anais do XXXVI Encontro da ANPAD. Rio de Janeiro, 22 a 26 de setembro.

Faria, J. H. de., \& Meneghetti, F. K. (2010). (Sem) saber e (com) poder nos estudos organizacionais. Cadernos EBAPE.BR, v.8, n.1, pp. 38-52.

Filho, D. S. R. (2011). Poder simbólico no reajuste tarifário do transporte metropolitano de passageiros de Porto Alegre na crise de 2004. Revista de Administração Pública, 45 (3): 643-68.

Francelin, M. M. (2005). Abordagens em epistemologia: Bacharelard, Morin e a epistemologia da complexidade. Transformação, Campinas 17 (2):101109, maio./ago.

Ganapati, N. E. (2012). Downsides of Social Capital for Women During Disaster Recovery: Toward a More Critical Approach. Administration \& Society 45(1) $72-96$.

Guljarani, N. (2010). New Vistas for Development Management: Examining Radical-Reformist Possibilities and Potential. Public Admin. Dev. 30 , 136-148.

Habermas, J. (1987). Teoría de la accióm comunicativa ll: crítica de la razón funcionalista. Tradución de Manuel Jiménez Redondo. Madrid, Taurus.

Howard, C. (2010). Are we being served? A critical perspective on Canada's Citizens First satisfaction surveys. International Review of Administrative Sciences, 76: 65

Horkheimer, M. (1975). Teoria Tradicional e Teoria Crítica. In: Coleção Os pensadores. São Paulo: Abril Cultural, pp. 125-162.

Imasato, T., Martins, P. E. M., \& Pieranti, O. P. (2011). Administrative Reforms and Global Managerialism: A Critical Analysis of Three Brazilian State Reforms. Canadian Journal of Administrative Sciences, 28: 174-187. 
Kasdan, D. O. (2012) "Great books" of public administration, 1990-2010: Revisiting Sherwood's survey in the wake of reinventing government. Administration \& Society 44, 625-639.

Keinert, T. M. M. (1994). Os paradigmas da administração da administração pública no Brasil (1900-1992). Revista de Administração de Empresas, v.34, n.3, p. 41-48, maio/jun

Klein, N. (2008). A doutrina do choque: a ascensão do capitalismo de desastre. trad. Vania Cury. Rio de Janeiro: Nova Fronteira.

Lima, L. A. de. (2011). A representação das Múltiplas Dimensões Paradigmáticas no Estudo da Administração: um ensaio sobre os limites contidos nas defesas paradigmáticas excludentes. Revista de administração contemporânea (RAC), Curitiba, v.15, n.2, art. 2, pp. 198208, Mar/Abr.

Lehner, O. M., \& Kaniskas, J. (2012). Opportunity Recognition in Social Entrepreneurship: A Thematic Meta Analysis. The Journal of Entrepreneurship, 21, 1, 25-58.

Lopes, A. L. M., \& Fracoll, L. A. (2008). Revisão sistemática de literatura e metassíntese qualitativa: considerações sobre sua aplicação na pesquisa em enfermagem. Texto Contexto Enferm, Florianópolis, OutDez; 17(4): 771-8.

Martins, R. D., \& FERREIRA, L. C. (2011). Uma revisão crítica sobre cidades e mudança climática: vinho velho em garrafa nova ou um novo paradigma de ação para a governança local?. Revista de Administração Pública, 45 (3): 611-41.

Marsden, R., \& Townley, B. (2001). Introdução: A coruja de Minerva: reflexões sobre a teoria na prática. In: CLEGG, S. R.; HARDY, C.; NORD, W. R. (Orgs.). Handbook de estudos organizacionais. São Paulo: Atlas, v. 2, pp. 31-56.

Mcclaren, P. G. \& Mills, J. H. (2010). Appropriation, Manipulation and Silence: A critical hermeneutic analysis of the management textbook as a tool of the corporate discourse. Management and Organization History, 5:408.

Mello, M. L. B. C., \& FILHO, A. A. (2010). A gestão de recursos humanos em uma instituição pública brasileira de ciência e tecnologia em saúde: o caso Fiocruz. Revista de Administração Pública, 44 (3): 613-36.

Mendonça, R. F. (2013). Teoria Crítica e democracia deliberativa: diálogos instáveis. Opinião Publica, v. 19, n. 1, pp. 49-64.

Miller, K. J., \& Mctavish, D. (2011). Women in UK Public Administration Scholarship. Public Administration, Vol. 89, No. 2, (681-697).

Misoczky, M. C., \& Amantino-de-Andrade, J. (2005). Uma crítica à crítica domesticada nos estudos organizacionais. Revista de Administração Contemporânea, v.9, n.1, pp. 193-210.

Mozzato, A. R., \& Grzybovski, D. (2013). Abordagem Crítica nos Estudos Organizacionais: Concepção de indivíduo sob a perspectiva emancipatória. Cadernos EBAPE.BR, v. 11, n. 4, artigo 1, Rio de Janeiro, Dez.

Nobre, M. (2011). A teoria crítica. 3. ed. Rio de Janeiro: Zahar

Oborne, D., \& Gaebler,T. (1994). Reinventando o Governo. Como o Espírito Empreendedor Está Transformando o setor público. Brasília: MH Comunicação.

Agradecimentos: Agradecemos a Fundação de Amparo a Pesquisa do Estado de Minas Gerais (Fapemig) pelo apoio financeiro.
Paes de Paula, A. P. (2008). Teoria Crítica nas Organizações. São Paulo: Thomson Learning, 2008.

Paes de Paula, A. P. (2013). Abordagem Freudo-Frankfurtiana, PesquisaAção e Socioanálise: uma proposta alternativa para os Estudos Organizacionais. Cadernos EBAPE.BR, v. 11, n. 4, artigo 2, Rio de Janeiro, Dez.

Paes de Paula, A. P., Maranhão, C. M. S. A., \& Barros, A. N. (2009). Pluralismo, pós-estruturalismo e "gerencialismo engajado": os limites do movimento critical management studies. Cadernos EBAPE.BR, v.7, n.3, pp. 393-404

Prasad, A. (2002). The contexto over Meaning: hermeneutics as na interpretative methodology for understanding texts. Organization Research Methods, 5:12.

Ramos, A.G. (1989). A nova ciência das organizações: uma reconstrução da riqueza das nações. Rio de Janeiro: Ed. FGV.

Ramos, A. G. (1965). A Redução Sociológica. Rio de Janeiro: Coleção Tempo Novo, 2 ed.

Raadschelders, J. C. N. (2011). The Future of the Study of Public Administration: Embedding Research Object and Methodology in Epistemology and Ontology. Public Administration Review, November December.

Raadschelders, J. C.N. (2012). What Are "Great Books" in the Study of Public Administration? Some Polemic Thoughts About the Surveys of Sherwood and Kasdan. Administration \& Society, 44: 894

Reis, P. M. \& Neto, P. A. B. (2013). Tráfico de seres humanos e trabalho forçado: uma abordagem crítica ao fluxo de informações utilizado pela Organização Internacional do Trabalho. Revista de Administração Pública, 47 (4): 975-98.

Sartori, E., \& Garcia, C. H. M. (2012). Políticas compensatórias versus emancipatórias: desafios para implementação de programas de geração de renda às famílias em situação de risco. Revista de Administração Pública, 46 (2): 425-52.

Sherwood, F. P. (1990). The half-century's "great books" in public administration. Public Administration Review, 50, 249-264.

Serva, M., Dias, T., \& Alperstedt, G. D. Paradigma da complexidade e Teoria das Organizações: Uma reflexão epistemológica. Revista de Administração de Empresas, São Paulo, v. 50, n.3, jul/set 2010, 276-287.

Sousa Santos, B. (1999). Porque é tão difícil construir uma teoria crítica? Revista Crítica de Ciências Sociais, Coimbra, n.54, 197-215, jun.

Tummers, L., \& Karsten, N. (2011). Reflecting on the Role of Literature in Qualitative Public Administration Research: Learning From Grounded Theory, Administration \& Society 44(1) 64-86 2012 SAGE Publications.

Zoltowski, A. P. C., Costa, A. B., Teixeira, M. A. P., \& Koller, S. H. (2014). Qualidade Metodológica das Revisões Sistemáticas em Periódicos de Psicologia Brasileiro. Psicologia: Teoria e Pesquisa, Jan-Mar, Vol. $30 \mathrm{n}$. 1, pp. 97-104. 